\title{
O lugar do pensamento crítico e criativo na formação de professores que ensinam matemática
}

\author{
Cleyton Hércules Gontijo*, Mateus Gianni Fonseca*
}

\section{Resumo}

Cada vez mais o pensamento crítico e criativo é defendido no cenário internacional como uma capacidade necessária para a educação do século XXI. No Brasil, esse assunto ainda é algo novo, sobretudo para os professores da educação básica. Com vistas a contribuir com o campo de formação de professores, planejou-se um conjunto de oficinas de pensamento crítico e criativo em matemática, realizado num contexto de formação continuada no espaço escolar, com 27 professores dos anos iniciais do ensino fundamental de uma escola de rede pública do Distrito Federal, de modo a analisar o potencial deste tipo de atividade como suporte ao trabalho docente com vistas ao estímulo do pensamento crítico e criativo dos estudantes. Neste trabalho, descrevemos uma dessas oficinas que explorou temática no campo das grandezas e medidas e proporcionalidade. As percepções reveladas pelos professores acerca da oficina demonstram que as atividades articulam adequadamente a base conceitual e metodológica, contribuindo positivamente com a formação docente e subsidiando a aplicação do modelo no trabalho com os estudantes.

Palavras-chave: Pensamento crítico e criativo em matemática; Criatividade em matemática; Formação continuada.

\footnotetext{
* Universidade de Brasília - UnB. Brasil. E-mail: cleyton@mat.unb.br

** Instituto Federal de Brasília - IFB. Brasil. E-mail: mateus.fonseca@ifb.edu.br
} 


\section{Introdução}

Desde o final do século 20 a criatividade passou a ser tema de interesse, não apenas para especialistas em educação, mas também para a sociedade em geral (CRAFT, 1999). A criatividade é um componente crucial para o desenvolvimento científico e tecnológico e é uma das principais fontes do desenvolvimento da sociedade (ROBINSON, 2001). Nesse sentido, deve ser incluída entre os objetivos educacionais como uma habilidade fundamental para a vida (CRAFT, 1999) que permitirá às novas gerações sobreviver e prosperar no século 21 (PARKHURST, 1999).

Dada a importância da criatividade, nossa sociedade espera legitimamente que os sistemas escolares favoreçam o desenvolvimento dessa habilidade nas nossas crianças e jovens e, para isso, espera-se que os professores também sejam criativos. Estudos mostram que professores criativos exercem influência positiva sobre 0 desenvolvimento da criatividade dos alunos (ROBINSON, 2001). Sternberg (2006) diz que o professor criativo pode ser um modelo para seus alunos, inspirando-os a adotar comportamentos e práticas de pensamento criativo semelhantes às suas ações.

Espera-se, portanto, que os processos de formação dos professores oportunizem o desenvolvimento de competências e habilidades criativas. Ressaltamos que a Resolução CNE/CP № 2, de 20 de dezembro de 2019, que define as Diretrizes Curriculares Nacionais para a Formação Inicial de Professores para a Educação Básica e que institui a Base Nacional Comum para a Formação Inicial de Professores da Educação Básica (BNC-Formação), apresenta dez competências gerais docentes e, entre elas, destaca: "Pesquisar, investigar, refletir, realizar a análise crítica, usar a criatividade e buscar soluções tecnológicas para selecionar, organizar e planejar práticas pedagógicas desafiadoras, coerentes e significativas" (Competência Geral 2 , grifos nossos).

Consideramos relevante um documento oficial, que estabelece diretrizes para formação de professores, indicar a criatividade como uma competência necessária para os docentes. Com essa inclusão, abre-se espaço para que estudos e práticas criativas sejam incluídos de forma sistemática nos cursos de licenciatura. Tal relevância reside no fato de que os professores podem apoiar o potencial criativo de seus alunos de uma infinidade de maneiras (RUNCO, 2007), por exemplo, sendo um modelo de atitude criativa, resolvendo problemas de forma original, comunicando valores que fomentam uma mentalidade criativa. Mas eles também podem 
inibi-lo, por exemplo, com práticas pedagógicas que focam na aquisição e repetição de conceitos e procedimentos operatórios (SIMPLÍCIO, 2000), com testes de conhecimento factual e não reflexivo (BEGHETTO, 2005). Os comportamentos e atitudes dos professores dependem em grande parte do apoio que recebem e do tipo de ambiente institucional a que pertencem, entre eles, dos processos de formação (CACHIA; FERRARI, 2010).

Em um estudo realizado com 7.659 professores de diferentes níveis de escolarização de 32 países europeus, Cachia e Ferrari (2010) apontaram que há uma discrepância entre o modo como os professores percebem a criatividade e a maneira como afirmam estimular a criatividade durante o ensino. As opiniões dos professores sobre criatividade na educação são mais fortes do que suas práticas. Segundo as autoras, isto implica que há muito espaço para melhorias na forma como a criatividade é fomentada nas escolas. Em relação à criatividade em matemática, Leikin (2009, 2010,2011 ) aponta que os estudos que envolvem as concepções dos professores estão subdesenvolvidos na pesquisa em educação matemática. Akta $\square$ (2015) sugere que testes padronizados, limitações curriculares e o sistema educacional atuam como algumas das barreiras sobre as práticas docentes para promoção da criatividade no cenário educacional.

No cenário brasileiro, no que diz respeito à criatividade em matemática, poucos trabalhos foram desenvolvidos. Segundo dados coletados junto à Biblioteca Digital Brasileira de Teses e Dissertações, do Instituto Brasileiro de Informação em Ciência e Tecnologia, nos últimos dez anos, entre teses e dissertações, apenas 17 produções foram defendidas no país. Os resultados foram obtidos utilizando o descritor "criatividade em matemática" nos campos "Título" e "Assunto". No primeiro caso, foram obtidos 16 trabalhos, com repetição de 3, resultando em 13 trabalhos. No segundo caso, foram obtidos 21 trabalhos, com repetição de 3, resultando em 18 trabalhos (desses, dois não têm relação com matemática - "Desenvolvendo criticidade e criatividade com estudantes de geografia por meio de modelagem" e "O Mapa da criatividade: validade de construto por meio da análise de redes"), resultando em 15 trabalhos. Comparando os resultados da busca com descritor "criatividade em matemática", considerando os campos "Título" e "Assunto", temos 20 trabalhos, sendo 17 trabalhos nos últimos dez anos. Dos 17 trabalhos encontrados, 3 são teses e 14 dissertações. Esses dados revelam, ainda, que 3 trabalhos focalizaram processos de formação e/ou atuação docente; 2 investigaram os anos iniciais do ensino fun- 
damental; 4 trabalhos tiveram os anos finais do ensino fundamental como objeto de análise e 8 relacionados ao Ensino Médio. Esses dados colocam em evidência o pequeno número de pesquisas sobre criatividade em matemática no Brasil desenvolvidas em Programas de Pós-Graduação.

Entre os trabalhos que investigaram os processos de formação e/ou atuação docente no Brasil, destacamos a pesquisa desenvolvida por Silva (2016), que após longo período de observação das práticas docentes em sala de aula, constatou indícios de estímulos que podem influenciar o desenvolvimento da criatividade matemática dos estudantes, todavia, esses estímulos são realizados de maneira intuitiva pelo professor, sem um planejamento sistemático de atividades voltadas para o desenvolvimento da criatividade dos estudantes.

Outro trabalho a ser destacado foi produzido por Farias (2015), que constatou que a percepção dos alunos acerca da avaliação escolar, bem como da metodologia de ensino utilizada pelo professor tem contribuído significativamente para o desenvolvimento da criatividade em matemática, entretanto, de forma negativa. Metodologias apoiadas numa concepção transmissiva de ensino como, por exemplo: "preocupa-se apenas com o conteúdo informativo", "utiliza sempre a mesma metodologia de ensino", "oferece aos alunos poucas opções de escolha com relação aos trabalhos a serem desenvolvidos”, não favorecem o desenvolvimento da criatividade no campo da matemática. Soh (2017), também reforça que a forma de atuação dos professores desempenha um papel fundamental na promoção da criatividade dos alunos.

Programas e/ou cursos de formação docente podem ser um caminho para mudanças nas práticas pedagógicas. Nesses espaços formativos, pode-se estimular algumas atitudes dos professores que promovem a criatividade: (a) incentivar os estudantes a aprender de forma independente; (b) ter um estilo de ensino cooperativo e socialmente integrador; (c) motivar seus estudantes a dominar o conhecimento factual para que eles tenham uma base sólida para o pensamento divergente; (d) não julgar as ideias dos estudantes até que elas tenham sido cuidadosamente trabalhadas e claramente formuladas; (e) incentivar o pensamento flexível; (f) promover a autoavaliação pelos estudantes; (g) oferecer oportunidades para os estudantes trabalharem com uma ampla variedade de materiais e sob diferentes condições e; (h) auxiliar os estudantes a aprender a lidar com a frustração e fracasso para que eles tenham a coragem para experimentar o novo e o incomum (CROPLEY, 1997). 
Considerando as lacunas apontadas na literatura acerca de processos formativos de docentes para o trabalho pedagógico com vistas ao estímulo à criatividade em matemática, desenvolvemos uma oficina com professores que atuam com crianças na faixa etária de 06 a 10 anos de idade para validar uma alternativa de formação docente para o estímulo do pensamento crítico e criativo das crianças no campo da matemática.

Para o desenvolvimento da oficina, consideramos as observações de Wechsler et. al. (2018) acerca do que constitui o pensamento crítico, trata-o como um constructo multidimensional, que implica em processos de raciocínio, tanto dedutivo quanto indutivo, para alcançar um resultado desejado. Consideramos ainda, de acordo com esses autores, que diferentes habilidades estão envolvidas no pensamento crítico, que dizem respeito a questionar a fonte do conhecimento, testar a validade das informações adquiridas, analisar a sua plausibilidade e propor explicações apropriadas para tarefas ou situações específicas.

Alguns autores destacam que, apesar de serem constructos diferentes, pensamento crítico está relacionado à criatividade. Lipman (2003), por exemplo, considera que o pensamento é intrinsecamente crítico e criativo, visto que existem fases nas quais se requer criatividade para gerar ideias novas e diferentes para a resolução de problemas; seguidas de etapas que exigem avaliação e tomadas de decisão no curso das ações, exigindo, assim, pensamento crítico. Dessa forma, os processos criativos interagem com os de pensamento crítico em diferentes fases do processo de resolução de problemas.

No que diz respeito à criatividade em Matemática, a consideramos como:

a capacidade de apresentar inúmeras possibilidades de solução apropriadas para uma situação-problema, de modo que estas focalizem aspectos distintos do problema e/ou formas diferenciadas de solucioná-lo, especialmente formas incomuns (originalidade), tanto em situações que requeiram a resolução e elaboração de problemas como em situações que solicitem a classificação ou organização de objetos e/ou elementos matemáticos em função de suas propriedades e atributos, seja textualmente, numericamente, graficamente ou na forma de uma sequência de ações (GONTIJO, 2007, p. 38).

Esse conceito tem se mostrado útil tanto para a pesquisa empírica quanto para o desenvolvimento de atividades práticas para serem desenvolvidas no cotidiano escolar. O conceito evidencia três dimensões que permitem a sua operacionalização: características do pensamento criativo (fluência, flexibilidade e originalidade), estratégias para estimular para estimular a criatividade (resolução de problema, 
elaboração de problemas e redefinição) e, formas de expressão do pensamento criativo (produção textual, numérica, gráfica ou sequência de ações).

Com vistas à ampliação conceitual, também passamos a considerar a definição apresentada por Fonseca e Gontijo (2020a) sobre o que caracteriza o pensamento crítico e criativo em matemática. Conforme os autores,

[...] a ação coordenada de geração de múltiplas e diferentes ideias para solucionar problemas (fluência e flexibilidade de pensamento) com o processo de tomadas de decisão no curso da elaboração dessas ideias, envolvendo análises dos dados e avaliação de evidências de que os caminhos propostos são plausíveis e apropriados para se chegar à solução, argumentando em favor da melhor ideia para alcançar o objetivo do problema (originalidade ou adequação ao contexto) (FONSECA; GONTIJO, 2020a, p. 971).

Nesse sentido, o pensamento crítico e criativo em matemática se manifesta pela capacidade de apresentar ideias apropriadas para resolver um problema e, ao mesmo tempo, comunicar essas ideias a partir de um argumento lógico, justificando-as. Para desenvolver essas habilidades, pode-se encorajar aqueles que estão a resolver problemas a descrever as suas soluções a partir de questões do tipo: (a) Como você descobriu a solução?; (b) Por que você acredita que a solução está correta?; (c) Essa solução funciona para todos os casos?; (d) Esse é o único caminho para alcançar a solução?; (e) Você poderia encontrar outras respostas?; (e) O que você observa em suas respostas?; (g) Elas apresentam um mesmo padrão?; (h) Você poderia propor uma resposta completamente diferente das anteriormente apresentadas?; (i) Conseguiria pensar em uma resposta incomum?; (j) Dentre as respostas que você criou, qual você considera a melhor e por quê? etc.

Dado o papel que a matemática desempenha no desenvolvimento científico e tecnológico, é fundamental estimular os estudantes para construir atitudes representações positivas em relação a essa disciplina e isso depende, em parte, das habilidades docentes para organizar o trabalho pedagógico de forma a tornar a matemática atrativa, inovadora e criativa.

\section{Método}

A oficina de formação para o estímulo do pensamento crítico e criativo de estudantes foi realizado com 27 professores de uma escola pública de uma região administrativa do Distrito Federal - Brasil, que trabalham com crianças na faixa 
etária de 6 a 10 anos de idade. Entre os participantes da oficina, 22 eram do gênero feminino e 5 do gênero masculino. Todos os participantes tinham curso de graduação, com predominância de formação no curso de Pedagogia. Um levantamento de informações no início da oficina revelou que apenas 2 professores tinham feito leituras e/ou participado de cursos destinados a discutir o tema criatividade no ambiente escolar.

Neste texto, será descrita uma atividade cuja temática central era o trabalho com proporções, conteúdo que está previsto na Base Nacional Comum Curricular - BNCC (BRASIL, 2017), que orienta a formulação dos currículos em todo o Brasil. Destaca-se, segundo a BNCC, que a proporcionalidade, deve estar, por exemplo, presente no estudo de:

[...] operações com os números naturais; representação fracionária dos números racionais; áreas; funções; probabilidade etc. Além disso, essa noção também se evidencia em muitas ações cotidianas e de outras áreas do conhecimento, como vendas e trocas mercantis, balanços químicos, representações gráficas etc. (p. 266).

Essa habilidade está presente no currículo escolar a partir do $4^{\circ}$ ano do ensino fundamental. Na oficina, enfatizou-se a habilidade de "resolver e elaborar problemas que envolvam porcentagens, com base na ideia de proporcionalidade, sem fazer uso da "regra de três", utilizando estratégias pessoais, cálculo mental e calculadora, em contextos de educação financeira, entre outros".

A oficina teve duração de 3 horas e foi desenvolvido a partir da seguinte questão motivadora: "Suponha que você é um gigante e que esse sapato enorme é seu, como você faria para saber qual é a sua altura?". Foi apresentada para os professores uma imagem presente no Livro dos Recordes - Guiness World Records (2012) correspondente ao maior sapato do mundo. Junto com a imagem, também foram apresentadas as dimensões do sapato.

A oficina contou com seis diferentes fases (GONTIJO, 2018), iniciando com atividades motivacionais, denominadas de "aquecimento", passando por um momento de sistematização dos conteúdos explorados durante resoluções de problemas, finalizando com tarefas que propõem uma continuidade da investigação, chamadas de perspectivas futuras. O infográfico a seguir, sintetiza cada uma das fases das oficinas: 
Figura 1 - Oficinas pedagógicas de pensamento crítico e criativo em matemática de Gontijo

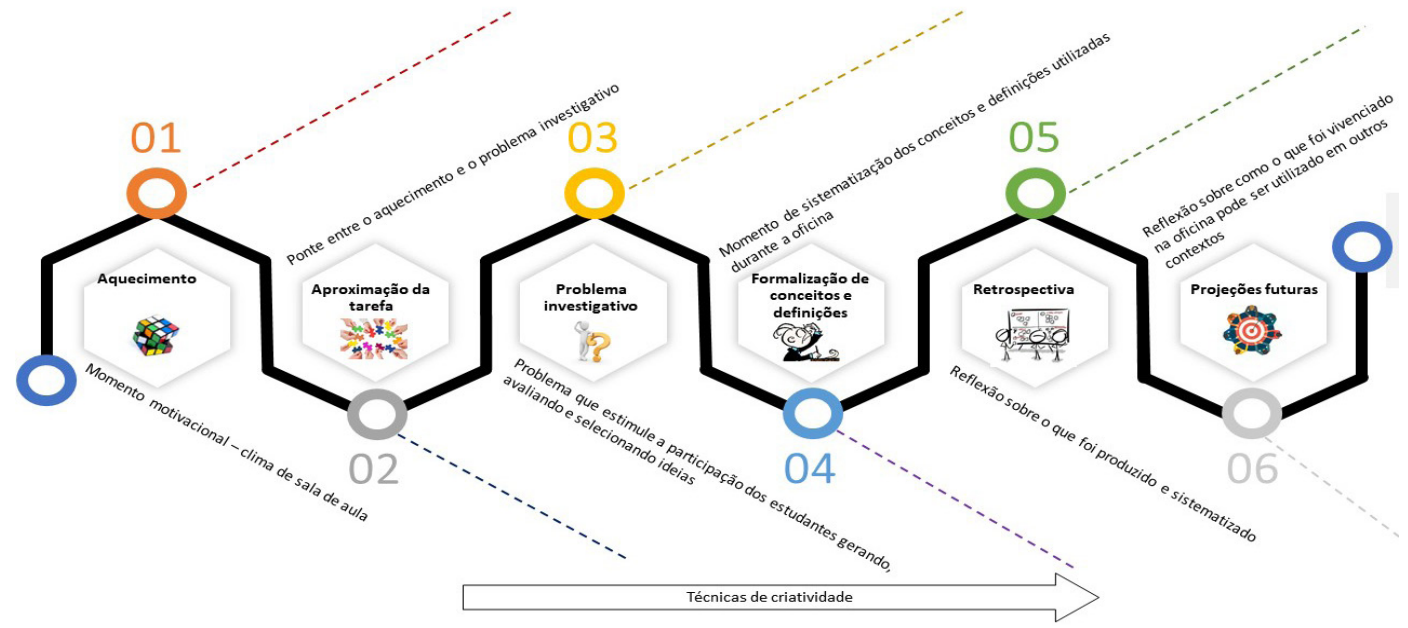

Fonte: Fonseca e Gontijo (2020b).

\section{1몰 Fase: Aquecimento}

Essa fase corresponde a uma atividade exploratória, de cunho motivacional, a fim de estimular os participantes a se envolverem com as próximas tarefas. Nessa oficina, trabalhamos com enigmas extraídos da obra de Stickels (2005), constituídos por imagens que deveriam ser decifradas (descritas) por meio de uma palavra ou frase. A técnica de criatividade brainstorming foi utilizada em algumas ocasiões para estimular os participantes na geração de ideias criativas para descrever os enigmas.

$2^{\text {a }}$ Fase: Aproximação com a tarefa

Nessa fase propõe-se uma atividade que aproxima os participantes da questão central a ser respondida ao longo da oficina. Como o problema envolvia "sapatos", buscou-se curiosidades sobre esse acessório e, para tanto, apresentou-se a figura da Haines Shoe House (uma casa em formato de sapato, construída na cidade de Hallam, Pensilvânia/USA), da High-Heel Church (uma igreja construída em formato de sapato de salto alto, com revestimento externo em vidro transparente, na cidade de Chiayi County, no sul de Taiwan) e, o maior sapato feminino do mundo. A partir desses exemplos, discutiu-se questões relacionadas a proporções na transformação de objetos de uso pessoal (sapatos) em obras arquitetônicas ou de arte em escala gigantesca. Esse momento é considerado importante para motivar os participantes para se envolverem com a tarefa, visto que a motivação é um componente importante do processo criativo. 
$3^{\text {a }}$ Fase: Desenvolvimento da tarefa - Problema Investigativo

Essa é a atividade principal desenvolvida junto com os participantes, tendo como objeto central a ação de resolução de problemas. A partir de algumas questões, os participantes produzem as suas soluções e argumentam acerca dos resultados encontrados, ou retornam ao início das atividades para reconstruir os caminhos trilhados, testar hipóteses e construir novas soluções. Essa etapa foi constituída das seguintes atividades:

a) Trabalho individual, com registro das hipóteses de solução em uma folha de papel (destaca-se que foi solicitado a elaboração de hipóteses, caminhos de solução e não a solução propriamente dita).

b) Trabalho individual de análise das hipóteses formuladas por um colega. Nessa atividade, os professores foram orientados a registrar na folha do colega as suas opiniões sobre as hipóteses apresentadas, fazendo-as de por meio de comentários positivos, mas sem deixar de manifestar as suas dúvidas e opiniões. Algumas expressões foram sugeridas para esse registro, tais como: Eu concordo com... porque...; Eu discordo com... porque...; Eu gostaria de acrescentar...; Eu percebi que...; Você poderia apresentar outro exemplo de...; Então, o que você está dizendo é...?; Você acha isso...?; Isso também não poderia ser...?; Por que você pensa isso?; Poderia explicar o que você disse...?; Poderia falar um pouco mais sobre isso...?

c) Retorno das produções aos seus respectivos autores. Cada participante analisa as opiniões que receberam e, se for o caso, registram novamente as suas ideias, incorporando as sugestões recebidas.

d) Divulgação das hipóteses e/ou caminhos de solução a partir da composição de um mural.

e) Todos os participantes se direcionam para o mural a fim de ler as produções dos colegas, classificando-as em: «bom», «melhor», «excelente», a partir de etiquetas coloridas (uma cor para cada tipo de classificação). Essa forma de classificação, segundo Dacey e Conklin (2013), tem por finalidade estimular a produção dos estudantes, evidenciando que todos têm condições de propor ideias matemáticas, ainda que algumas dessas possam ser mais apropriadas do que as demais.

f) Seleção das hipóteses e/ou estratégias consideradas mais apropriadas para a solução do problema, sem a interferência dos pesquisadores. 
4" Fase: Sistematização - Formalização de conceitos e definições

Após a seleção das hipóteses pelos participantes, os pesquisadores entram em cena problematizando a escolha e oferendo os subsídios necessários para a resolução do problema, levando à sistematização dos conceitos/definições envolvidas na atividade.

$5^{\text {a }}$ Fase: Retrospectiva

Essa fase se caracteriza pela revisão de todas as atividades realizadas ao longo da oficina, levando os estudantes a refletirem sobre todas as suas ações, destacando as aprendizagens ocorridas. Busca-se nessa fase, recolher depoimentos relativos às experiências de aprendizagem, como as atividades que mais apreciaram e as que menos apreciaram e os motivos relacionados a essas experiências.

6 ${ }^{\mathrm{a}}$ Fase: Projeções futuras

Essa fase consiste em possibilitar aos estudantes continuar explorando os temas trabalhados na oficina nos demais contextos em que estão inseridos. Nesse último momento da oficina, discutiu-se acerca de como conduzir atividades semelhantes junto aos estudantes de 6 a 10 anos de idade.

\section{Resultados e discussão}

Nessa seção, vamos apresentar algumas falas produzidas na durante o desenvolvimento da tarefa, evidenciando diálogos entre os professores participantes a atividade e, em seguida, apresentaremos a avaliação que estes participantes fizeram da oficina, revelando as suas percepções sobre as atividades e suas potencialidades para a formação de professores e adaptação e aplicação para o trabalho com os estudantes dos anos iniciais do ensino fundamental.

A seguir, alguns exemplos de hipóteses e/ou caminhos de resolução propostos pelos participantes da oficina e os comentários apresentados pelos colegas:

Professor A: Mediria o tamanho do pé com fita métrica para descobrir o tamanho do sapato.

Professor B: Não compreendi a sua estratégia, pois, não é o tamanho do pé a ser medido. É a sua altura que deve ser calculada.

Professor A: Pela medida do tamanho do meu pé na fita métrica, estimaria o tamanho do sapato. 
Neste primeiro diálogo podemos notar que o Professor A apresentou uma estratégia que não o ajudaria a resolver o problema proposto visto que o número do sapato já tinha sido informado. O equívoco pode ter se dado pela falta de interesse e engajamento do Professor A para com a atividade. Com isso podemos notar que a motivação muitas vezes é um fator decisivo quando se está participando de uma oficina que requer a aplicação do pensamento crítico e criativo.

Professor C: Iria dobrar o número do sapato e o número da altura até aproximar do tamanho do sapato gigante.

Professor D: Eu gostei da sua estratégia, mas não entendi por que multiplicar por 2.

Professor C: Bem, não seria suficiente multiplicar por dois apenas uma vez. Teria que fazer isso até chegar no tamanho certo.

A solução apresentada pelo Professor C não é precisa, mas podemos inferir que ela traz minimamente uma noção de proporcionalidade no raciocínio. O que faltou explicar foi a escolha do fator multiplicativo. O professor não criou uma estratégia matemática apropriada para determiná-lo e por isso apresentou uma solução intuitiva, tanto que foi questionado a respeito desta escolha pelo Professor D.

Professor E: Dividi o número da minha altura pelo tamanho do meu pé. Encontrei como resultado 4,5. Então multipliquei esse valor pelo tamanho do sapato gigante. Terei como altura $3.388,5 \mathrm{~cm}$.

Professor F: Entendi o que você pensou. Gostei da sua estratégia.

Professor E: Quero acrescentar que fiz essa mesma estratégia com outras pessoas. Descobri que em todos os resultados a escala gira em torno de 4,3 a 4,5. Ou seja, a altura é cerca de 4 vezes maior que o tamanho do pé.

Uma solução adequada foi mostrada pelo Professor E. Aqui o participante da atividade fez uso da proporcionalidade de forma apropriada, inclusive, a noção de escala, o que era de fato o conteúdo que queríamos trabalhar. No que tange ao pensamento crítico e criativo em matemática, o Professor E não se contentou apenas em encontrar uma solução do problema, mas buscou investigar se a sua estratégia também seria válida a partir das medidas de outros participantes, demonstrando uma capacidade de refinamento/elaboração de sua resposta. Registramos, entretanto, a necessidade de um refinamento no que diz respeito à terminologia utilizada pelo professor E, por exemplo: "dividi o número da minha altura" poderia ser registrado como "dividi a medida da minha altura"; o "tamanho do meu pé" poderia ser o "número do meu calçado". 
Professor G: A minha altura atual dividida pelo tamanho do meu pé corresponde a $4 \mathrm{~cm}$. Minha altura será de aproximadamente 4 vezes o tamanho do meu pé gigante.

Professor H: Gostei, mas não compreendi o raciocínio; o resultado deu em centímetros. O número do sapato seria descoberto como?

Professor G: Exemplo: peguei a minha altura que é $163 \mathrm{~cm}$ e dividi pelo número do meu tênis, que é 36. Encontrei aproximadamente 4,53. Daí, fiz a conta 4,53 x 753 =3409. Como esse resultado estava em centímetros, transformei para metros e deu $3,40 \mathrm{~m}$ de altura.

A estratégia do Professor G também foi adequada, todavia, a forma de explicá-la não foi muito "didática". O Professor $\mathrm{H}$ a princípio não entendeu a estratégia do Professor G, que para se fazer compreendido, usou um exemplo prático. A indagação do Professor $\mathrm{H}$ pode revelar indícios de que não domina estratégias para determinar estimar valores e/ou trabalhar com proporcionalidade ou que não compreendeu devidamente a tarefa e as informações que foram prestadas. Em qualquer das hipóteses, podemos dizer que a formação continuada em serviço, no coletivo da própria escola, pode se converter em uma rica oportunidade para o aprendizado docente em relação à matemática, às estratégias de ensino de ensino e, ainda, à construção de um clima favorável ao planejamento coletivo do trabalho docente.

Ressaltamos que alguns professores confundiram as dimensões que deveriam ser utilizadas para encontrar uma proporção adequada, gerando respostas inadequadas. Identificar as dificuldades apresentadas pelos professores foi de extrema importância para a fase final do exercício, a de sistematização. Assim, puderam sanar possíveis dificuldades teóricas bem como obter esclarecimentos sobre procedimentos e técnicas operatórias que poderiam ser aplicadas para obter a solução do problema.

Usando a solução descrita no terceiro exemplo como base e analisando as outras hipóteses corretas podemos sistematizar a tarefa, sanando as dúvidas e explicando as habilidades trabalhadas na atividade. Além disso, ao final também houve uma discussão a respeito de como esta oficina poderia ser adaptada para alunos da educação básica, para que os professores trabalhassem com suas respectivas turmas de maneira adequada.

Ao final da oficina, foi distribuído um formulário para avaliação, por meio do qual os participantes manifestaram suas percepções acerca das atividades desenvolvidas. Para cada item avaliado, os respondentes poderiam escolher por uma das cinco respostas: 1 - ótimo; 2 - bom; 3 - regular; 4 - ruim; 5 - péssimo. No que diz respeito ao tópico matemático abordado, $83,3 \%$ informaram que a abordagem foi 
ótima e para 16,7\% essa abordagem foi boa. Em relação à clareza na apresentação e à qualidade das atividades realizadas, $100 \%$ dos respondentes indicaram que estas foram ótimas.

As avaliações deixaram de apresentar unanimidade quando o quesito avaliado foi a aplicabilidade da oficina na prática docente com os estudantes, todavia, as respostas ainda foram positivas. Para 58,3\% dos respondentes consideram "ótima" a possibilidade de aplicação enquanto para 41,7\% essa aplicação foi considerada "boa". Ajustificativa para a classificação como "boa" reside no fato da falta de confiança na replicação/adaptação da oficina, na quantidade de tempo necessário para executá-la e na falta de ambiente apropriado para desenvolver atividades diferenciadas. Essas explicações estão coerentes com os aspectos apontados por Aktaş (2015) que atuam como barreiras para promover a criatividade no cenário educacional.

De acordo com a boa avaliação da oficina, depreende-se a aceitação por parte do grupo desse tipo de atividade formativa. Ademais, os depoimentos coletados permitem entender a imersão que os professores estavam naquele momento acerca do pensamento crítico e criativo em matemática. Conhecer uma atividade que estimula o que se chama de pensamento crítico e criativo foi novidade para este grupo de professores. Podemos inferir, a partir das manifestadas dos professores, que eles se sentiram provocados a levar este tipo de atividade para as suas salas de aula.

\section{Considerações finais}

A realização desse tipo de oficina com esse grupo de professores sinaliza algumas contribuições para o campo da formação docente: a primeira se refere ao potencial que o modelo de oficinas de pensamento crítico e criativo tem para ser utilizado em outros processos de formação continuadas de professores para que esses possam ter um primeiro contato com a temática em questão.

Uma segunda contribuição diz respeito a necessidade da criação de um programa de formação de professores com vistas a apresentar o conceito de pensamento crítico e criativo e permitir que tais profissionais possam vivenciar estratégias para o estímulo a esse tipo de pensamento. Afinal, para se estimular a criatividade em matemática dos novos estudantes, é necessário se estimular a criatividade em matemática junto aos professores. 
A fim de serem capazes de estimular a criatividade matemática de seus alunos, os professores devem adquirir conhecimentos pedagógicos adequados durante a formação inicial e estes devem ser aprimorados ao longo da carreira por meio de programas de formação continuada. No que diz respeito ao pensamento crítico e criativo, muitos professores admitem a falta de experiência anterior ou preparação adequada estimular esse tipo de pensamento em seus alunos. Os programas de formação precisam explorar explicitamente o que significa pensar de forma crítica e criativa para que os professores se sintam, primeiramente, criativos, para poderem se sentir capazes de estimular o pensamento crítico e criativo em seus alunos.

\section{Critical and creative thinking on the education of teachers who teach Mathematics}

\section{Abstract}

Increasingly, critical and creative thinking is defended on the international stage as a necessary capacity for 21st century education. In Brazil, this subject is still something new, especially for basic education teachers. In order to contribute to the field of teacher training, a set of workshops on critical and creative thinking in mathematics was planned, carried out in a context of in-service teacher training, with 27 teachers from the early years of elementary school in a school of public network of the Federal District, looking to analyze the potential of this type of activity in support of teaching work with a view to stimulating students' critical and creative thinking. In this work, we describe one of those workshops that explored thematic in the field of quantities and measures and proportionality. The perceptions revealed by the teachers about the workshop demonstrate that the activities adequately articulate the conceptual and methodological basis, contributing positively to teacher training and subsidizing the application of the model in working with students.

Keywords: Creative and critical thinking in mathematics; Mathematical creativity; In-service teacher training.

\section{Referências}

AKTAŞ, Meral Cansız. Turkish high school teachers' conceptions of creativity in mathematics. Journal of Education and Training Studies, Beaverton, v. 4, n. 2, p. 42-52, Feb/2016.

BEGHETTO, Ronald A. Does Assessment Kill Student Creativity? The Educational Forum, v. 69, p. 254-263, 2005.

BRASIL. Ministério da Educação. Base nacional comum curricular: Educação é a base. Brasília: MEC, 2017. 
CACHIA, Romina; FERRARI, Anusca. Creativity in schools: a survey of teachers in Europe. European Commission / Joint Research Centre, Luxembourg: Publications Office of the European Union, 2010.

CRAFT, Anna. Creative development in the early years: some implications of policy for practice. Curriculum journal, v. 10, n. 1, p. 135-150, 1999.

CROPLEY, Arthur J. (1997). Fostering creativity in the classroom: General principles. In M. A. Runco (Ed.) Creativity research handbook (Vol. 1, pp.83-114). Cresskill, N. J.: Hampton Press.

DACEY, Jonh; CONKLIN, Wendy. Creativity and the standards. Huntington Beach: Shell Education, 2013.

FARIAS, Mateus Pinheiro de. Criatividade em matemática: um modelo preditivo considerando a percepção de alunos do ensino médio acerca das práticas docentes, a motivação para aprender e o conhecimento em relação à matemática. 2015. 75 f. Dissertação (Mestrado em Educação) Universidade de Brasília, Brasília.

FONSECA, Mateus Gianni; GONTIJO, Cleyton Hércules. Pensamento crítico e criativo em Matemática em diretrizes curriculares nacionais. Ensino em Re-Vista, Uberlândia, v. 27, p. 956-978, 2020a.

FONSECA, Mateus Gianni; GONTIJO, Cleyton Hércules. Junho 2020. Infográfico: Oficinas de estímulo ao pensamento crítico e criativo em matemática de Gontijo. Disponível em: <https://bit. ly/pensamentocriticoecriativoemmatematica>. Acesso em 24 set. $2020 \mathrm{~b}$.

GONTIJO, Cleyton Hércules. Relações entre criatividade, criatividade em matemática e motivação em matemática de alunos do ensino médio. 2007. 194f. Tese (Doutorado em Psicologia) - Instituto de Psicologia, Universidade de Brasília, Brasília.

GONTIJO, Cleyton Hércules. Roteiro para Oficinas de Criatividade em Matemática. Brasília, 2018. Não publicado.

GUINESS WORLD RECORDS. São Paulo: Editora Três Ltda, 2012.

LEIKIN, Roza. Exploring mathematical creativity using multiple solution tasks. In R. LEIKIN, A. BERMAN, \& B. KOICHU (Eds.). Creativity in mathematics and the education of gifted students (pp. 129-145). Rotterdam: Sense Publishers, 2009.

LEIKIN, Roza. Teaching mathematically gifted. Gifted Education International, v. 27, p. 161-175, 2010.

LEIKIN, Roza. The education of mathematically gifted students: On some complexities and questions. Montana Mathematical Enthusiast Journal, v. 8, p. 167-188, 2011.

LIPMAN, Matthew. Thinking in education. UK: Cambridge University Press, 2003.

PARKHURST, Howard B. Confusion, lack of consensus, and the definition of creativity as a construct. Journal of Creative Behaviour, v. 33, n. 1, p. 1-21, 1999.

ROBINSON, Ken. Out of Our Minds: Learning to Be Creative. John Wiley \& Sons, 2001.

RUNCO, Mark A. (2007). Creativity: theories and themes: research, development, and practice. Amsterdam; London: Elsevier Academic Press.

SIMPLICIO, Joseph S. C. Teaching classroom educators how to be more effective and creative teachers. Education, v. 120, n. 4, p. 675-680, 2000. 
SOH, Kaycheng. Fostering student creativity through teacher behaviors. Thinking Skills and Creativity, v. 23, p. 58-66, 2017.

SILVA, Fabiana Barros de Araújo. Trabalho pedagógico e criatividade em matemática: um olhar a partir da prática docente nos anos iniciais do ensino fundamental. 2016. 134f. Dissertação (Mestrado em Educação) - Universidade de Brasília, Brasília.

STERNBERG, Robert J. The nature of creativity. Creativity Research Journal, v. 18, n. 1, p. 87-98, 2006.

WECHSLER, Solange Muglia; SAIZ, Carlos; RIVAS, Silvia Fernandez; VENDRAMINI, Claudete Maria Medeiros; ALMEIDA, Leandro S.; MUNDIM, Maria Celia; FRANCO, Amanda. Creative and critical thinking: Independent or overlapping components? Thinking Skills and Creativity, Amsterdam, v. 27, p. 114-122, 2018. 